\title{
Buku Al-Arabiyyatu Bayna Yadaik (Analisis Pengajaran Bahasa Arab Dalam Perspektif Lintas Budaya)
}

\author{
Siti Rohmah Soekarba
}

emma.soekarba1946@gmail.com

Prodi Arab/Fakultas Ilmu Budaya

Universitas Indonesia

• Received: 01.10.2019 • Accepted: 31.10 .2019 • Published online: 05.11.2019

Abstract: The purpose of this paper is to analyze Arabic teaching methods at the Faculty of Cultural Sciences, University of Indonesia, which uses the book Al-Arabiyyatu bayna Yadaik in the perspective of Cross Cultural Understanding which is assumed to reduce stagnation in conversation and respect for other people's culture by selecting textbooks used as handbooks. Arabic is a reflection of Arabic culture. Three approaches in teaching Arabic are through language, psychology, and sociolinguistics (culture). The teaching of Arabic culture can be applied through listening, conversation, reading and writing material. The research method used is a descriptive qualitative analysis. The conclusion of this article is that the book AlArabiyyatu bayna Yadaik displays four competencies, namely listening skills (maharatu al-istima'), reading (maharatu al-qira'ah), speaking (maharatu alkalam), and writing (maharatu al-kitabah), in addition to additional knowledge in the form of language about Arabic and Islamic culture that can be used as an alternative to cross-cultural Arabic-based learning.

Keywords : Arabic, Al-Arabiyyatu bayna Yadaik, competence, Arabic culture

\section{Pendahuluan}

Bahasa Arab adalah pilar keanekaragaman budaya umat manusia. Bahasa ini adalah salah satu bahasa yang digunakan setiap hari oleh lebih dari 290 juta orang di seluruh dunia. Sejak 2012, Hari Bahasa Arab Sedunia diperingati setiap tahun pada 18 Desember. Tanggal tersebut bertepatan dengan hari pada 1973 ketika Majelis Umum Perserikatan Bangsa-Bangsa mengadopsi bahasa Arab sebagai bahasa resmi keenam PBB. (unesco.org, 2017) 
Dalam keragaman bentuknya, klasik atau dialek, dari ekspresi lisan hingga kaligrafi puitis, bahasa Arab telah memunculkan estetika yang memesona, dalam bidang yang beragam seperti arsitektur, puisi, filsafat, dan lagu. Hal ini memberikan akses ke berbagai identitas dan kepercayaan yang luar biasa dan sejarahnya mengungkapkan kekayaan hubungannya dengan bahasa lain. Bahasa Arab telah memainkan peran katalitik dalam pengetahuan, mempromosikan penyebaran ilmu-ilmu dan filsafat Yunani dan Romawi ke era Renaisans di eropa yang telah memungkinkan dialog budaya di sepanjang jalan sutra, dari pantai India ke Tanduk Afrika.

Keterkaitan Bahasa Arab dan Islam sperti dua sisi mata uang yang saling berkaitan. Sejarah Indonesia banyak mencatat bahwa hadirnyanya Islam di Nusantara pada abad XVII diyakini sebagai alasan utama membuminya bahasa Arab di Indonesia sejak sebagai salah satu bahasa asing yang memberi pengaruh kebahasaan pada aspek bahasa Indonesia dan sastranya (Hadi, 1995; Kuipers \& Askuri, 2017; Rahmi, 2018). Karena itu mendiskusikan bahasa Arab di Indonesia pun tidak pernah ada batasannya selama Islam dipeluk oleh mayoritas penduduk Indonesia lantaran umat Islam menggunakan bahasa Arab dalam kewajiban menjalankan ibadah salat dan memanjatkan doa-doa, sehingga bahasa Arab tidak dapat dipisahkan dari Islam (Letmiros, 2019).

Meskipun bahasa Arab identik dengan umat Islam tetapi para pembelajar bahasa Arab baik di universitas, Lembaga Bahasa Internasional (LBI), Sekolah Pendidikan Luar Negeri (Sekdilu) dan lain-lain tidak semuanya beragama Islam. Mereka mempelajari bahasa Arab sebagai tuntutan karir sebagai calon diplomat, bahasa Arab sebagai bahasa ilmiah, bahkan terdapat pembelajar yang ingin mengenal bahasa Arab hanya di dorong rasa penasaran mereka terhadap Islam.

Namun, hal itu tidak mengesampingkan kemungkinan bagi pembelajar yang ingin melihat masalah budaya di negara-negara Arab, terutama Arab Saudi, pusat Islam dan tempat banyak sumber buku teks keagamaan dicetak. Karena itu ruang lingkup tulisan ini adalah hal-hal yang berkaitan dengan budaya Islam dan budaya Arab 
dengan berbagai aspek yang dimuat di dalam buku teks pembelajaran bahasa Arab. penelitian ini ditujukan menganalisis pengajaran bahasa Arab di tingkat perguruan tinggi dari perspektif lintas budaya dengan ancangan studi kasus pada buku pelajaran Al-Arabiyyatu bayna Yadaik $(A b Y)$ jilid I di Fakultas Ilmu Budaya Universitas Indonesia (FIB UI).

Penelitian ini berangkat dari keinginan pembelajar dalam mempelajari bahasa Arab dengan menggunakan sistem pengajaran modern yang sesuai dengan kondisi mereka sebagai mahasiswa milenial urban. Para pembelajar awal di FIB UI menemukan kesulitan ketika belajar bahasa Arab menggunakan metode klasik, di antaranya ada metode terjemahan dan metode gramatika.

Kehadiran buku Al-Arabiyyatu Bayna Yadaik menjawab kebutuhan akan metode pembelajaran bahasa Arab modern. Di awal pelajaran native speaker meminta pembelajar untuk mendengarkan terlebih dahulu, kemudian meminta mereka untuk menirukannya. Hal ini sesuai dengan pengertian bahasa bahwa bahasa adalah sebagaimana dikatakan penutur asli, bukan seperti yang dipikirkan orang bagaimana seharusnya berbicara(Aziez \& Al-Wasilah, 1996).

Dengan demikian, pembelajar langsung mempraktikan yang dipikirkan orang bahasa Arab tanpa harus berpikir rumit aturanaturan gramatika dan sebagainya. Di samping itu, dengan tanpa disadari pembelajar mempraktikkan budaya Islam seperti ucapan salam di awal dan di akhir percakapan.

\section{Metode}

Metode yang digunakan dalam penulisan artikel ini adalah metode deskriptif-analitis kuantitatif. Langkah-langkah penelitian dimulai dengan membaca buku teks sebagai sumber primer dengan seksama, membuat kategori-kategori yang sesuai dengan tujuan penelitian ini seperti budaya Islam dan budaya Arab, menganalisis dan menyimpulkannya. sumber utama adalah Al-Arabiyyatu bayna Yadaik (AbY) jilid I karya Dr. Abdul Rahman Ibn Ibrahim Al-Fawzan, Dr. Mukhtar Al-Tahir Hussain, Dr. Muhammad Abdul Khaliq Muhamad Fadhl, dan disunting oleh Dr. Mohammed Ibn Abdul Rahman Al-Shaikh, diterbitkan di Riyadh, Arab Saudi oleh Al- 
Arabiyyah li al-Jami'. Buku Al-Arabiyyatu bayna Yadaik yang dibahas dalam makalah ini dijadikan sebagai korpus bahasa. Tentu seperti yang dipapakan oleh Ainin (2007) bahwa unsur subjektivitas peneliti ikut mewarnai penelitian ini dalam pemilihan kasus. Kendati demikian, kajian diupayakan secara mendalam dan utuh dalam kasus yang diteliti dan akan melahirkan hipotesa-hipotesa pada penelitian selanjutnya. Selain sumber utama artikel ini juga menggunakan sumber sekunder dan tersier berbentuk buku dan jurnal.

Dalam analisis data peneliti mengunakan Analysis Interactive Model Miles \& Huberman (2007) yang membagi langkah-langkah dalam kegiatan analisis data dengan beberapa bagian yaitu pengumpulan data (data collection), reduksi data (data reduction), penyajian data (data display), dan penarikan kesimpulan atau verifikasi (conclutions).

\section{Hasil dan Pembahasan}

\subsection{Deskripsi Buku Al-Arabiyyatu bayna Yadaik}

Buku Al-Arabiyyatu bayna Yadaik dikarang oleh Dr. Abdul Rahman Ibn Ibrahim Al-Fawzan, Dr. Mukhtar Al-Tahir Hussain, Dr. Muhammad Abdul Khaliq Muhamad Fadhl, dan disunting oleh Dr. Mohammed Ibn Abdul Rahman Al-Shaikh, diterbitkan di Riyadh, Arab Saudi oleh Al-Arabiyyah li al-Jami'. Buku ini terdiri dari 3 volume yang dilengkapi dengan audio berupa kaset dan MP3 CD.(AlFauzan, Husain, \& Fadhl, 2004) 


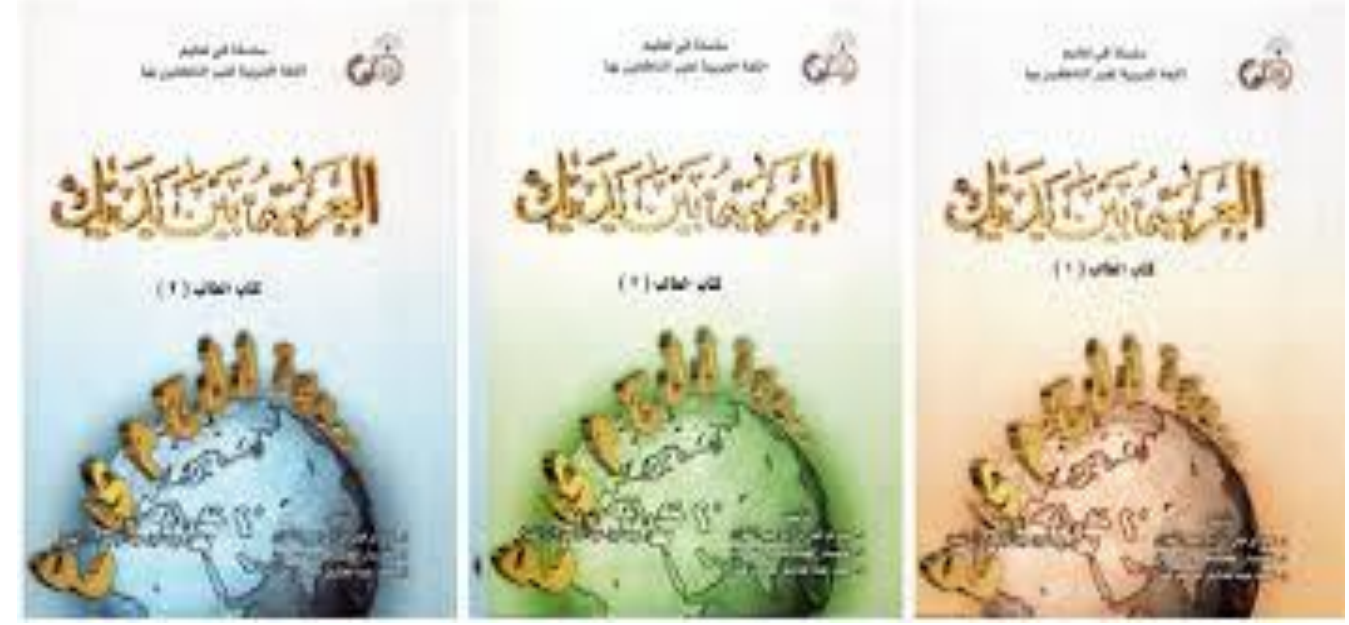

Gambar 1 Tampilan Buku Al-Arabiyyatu bayna Yadaik Jilid 1, 2 dan 3

Tujuan buku Al-Arabiyyatu bayna Yadaik adalah membuat pembelajar menguasai kemampuan berbahasa, kemampuan berkomunikasi, dan kemampuan memahami budaya. Kemampuan berbahasa yang disasar adalah empat kemampuan utama yaitu (1) Kemahiran mendengar (maharatu al-sima'); (2) Kemahiran berbicara (maharatu al-kalam); (3) Kemahiran membaca (maharatu al-qira'ah); dan (4) Kemahiran menulis (maharatu al-kitabah). Unsur-unsur bahasa yang ditampilkan adalah sistem suara (aswatu al-huruf), kosakata (mufradat), kaidah-kaidah nahwu dan sharaf dan penulisan kata (imla').

Kemampuan berkomunikasi dimaksudkan agar para pengguna buku ini mampu bercakap-cakap dengan bahasa Arab dan dapat mengekspresikan ide secara lisan dan tulisan ( $t a^{\prime} b i r$ syafawi dan tahriri) serta mampu menyusun kalimat dan ungkapan dalam situasi sehari-hari. Kemampuan memahami budaya diperkenalkan dengan berbagai sisi kebudayaan Arab dan prinsip-prinsip Islam.

Buku ini ditujukan untuk para pelajar dan mahasiswa apakah mereka terikat dalam satu institusi pendidikan atau belajar mandiri, dapat dilakukan program pembelajaran yang intensif maupun nonintensif. Buku ini juga dapat digunakan untuk para pembelajar yang sama sekali belum pernah mengenal bahasa Arab (pemula) dengan menampilkan pengajaran mulai dari dasar (mendengar, berbicara, menulis, dan membaca) sampai mampu berkomunikasi 
dengan para pengguna bahasa Arab secara lisan dan tertulis. Hal ini memungkinkan bagi mereka yang hendak melanjutkan pendidikan di universitas-universitas di negara-negara Arab yang menggunakan bahasa Arab sebagai bahasa pengantar kuliah.

Ragam bahasa yang digunakan dalam buku ini adalah bahasa Arab baku (fashih, fusha). Tidak ada sama sekali unsur bahasa tidak baku ('amiyyah), dan tidak digunakan bahasa perantara sebagai sebuah cara dalam pengajaran bahasa. Buku ini terbagi dalam tiga tingkatan yaitu tingkat dasar (marhalatu al-mubtadiin), tingkat menengah (marhalatu al-mutawassithin), dan tingkat mahir (marhalatu al-mutaqaddimin). Masing-masing tingkatan tersedia satu buku untuk pengajar (kitab al-mudarris) dan buku untuk pembelajar (kitab al-thalib) yang dilengkapi dengan panduan audio. Waktu untuk menyampaikan seluruh pelajaran dalam kitab-kitab ini adalah 300 jam pelajaran (satu jam pelajaran adalah 50 menit). Artinya, setiap level adalah 100 jam pelajaran Materi pelajaran di dalam buku ini bila disampaikan dalam program yang tidak intensif, maka dibutuhkan waktu 3 tahun. Metode yang digunakan dalam buku ini adalah metode pembelajaran yang modern seperti prinsip pembelajaran dan pengajaran bahasa asing dengan tetap memperhatikan karakteristik khusus dan unik bahasa Arab. Di dalam buku ini diperlihatkan halhal berikut:

1. Keterpaduan antara keahlian berbahasa dan unsur-unsur yang terdapat di dalamnya.

2. Memberikan perhatian pada sistem suara dalam bahasa Arab (al-ashwat wa fahmu al-masmuq)

3. Memperhatikan proses gradasi dan tahapan dalam menyampaikan materi pelajaran.

4. Memperhatikan perbedaan-perbedaan individu di antara para pembelajar.

5. Menyertakan latihan-latihan (tadribat) yang beragam.

6. Kesesuaian kandungan dengan tingkatan pembelajar.

7. Menggunakan sistem unit-pelajaran dalam menyampaikan materi.

8. Menampilkan setiap kosakata dalam susunan yang sempurna. 
9. Memperhatikan kemampuan pengucapan pada tingkat lanjut.

10. Menyertakan daftar kosakata dan ungkapan-ungkapan yang terdapat dalam setiap kitab.

11. Menyertakan latihan berkala dalam setiap kitab.

12. Memanfaatkan berbagai pengalaman khusus dalam menyusun materi-materi pelajaran bahasa Arab dan bahasa-bahasa lain.

13. Menampilkan nilai-nilai budaya Arab dan Islam dengan cara yang menarik.

14. Menggunakan banyak gambar, khususnya dalam buku pertama yang mengandung lebih dari 1000 gambar penjelas.

Dengan menggunakan buku Al-Arabiyyatu bayna Yadaik, para pembelajar ditargetkan akan mampu secara bertahap untuk membaca tulisan Arab tanpa tanda baca (harakat, syakl). (Al-Fauzan et al., 2004)

Metode yang digunakan di dalam buku ini tidak disandarkan pada metode gramatikal, metode terjemahan, namun perpaduan (eklektik) antara metode langsung dan metode audio lingual. Effendi (2005) berargumen bahwa penggabungan metode lebih tepat dilakukan dalam tataran teknik dan operasional.

\subsection{Nilai-Nilai Budaya Arab dan Islam dalam Buku Al-Arabiyyatu Bayna Yadaik}

Buku ini terdiri atas bab 16 dan 401 halaman. Tema-tema yang dibicarakan dalam buku I adalah:

1. Al-Tahiyya wa Ta'aruf (Salam dan Perkenalan)

2. Al-Usratu (Keluarga)

3. Al-Sakan (Tempat Tinggal)

4. Al-Hayatu al-Yaumiyyah (Kehidupan Sehari-hari)

5. Al-Ta'am wa al-Syarab (Makanan dan Minuman)

6. Al-Salah (Salat)

7. Al-Dirasah (Pelajaran Sekolah)

8. Al-'Amal (Pekerjaan)

9. Al-Tasawwuq (Berbelanja)

10. Al-Jawwu (Cuaca)

11. Al-Nas wa al-Amakin (Orang dan Tempat-tempat)

12. Al-Hiwayat (Hobi) 
Siti Rohmah Soekarba

13. Al-Safar (Bepergian)

14. Al-Haj wa al-'Umrah (Haji dan Umrah)

15. Al-Sihhah (Kesehatan)

16. Al-`Utlah (Liburan)

Bab I Al-Tahiyya wa Ta'aruf (Salam dan Perkenalan)

\begin{tabular}{|c|c|}
\hline Budaya Arab & Budaya Islam \\
\hline $\begin{array}{l}\text { Percakapan laki-laki dengan } \\
\text { laki-laki, percakapan perempuan } \\
\text { dengan perempuan }\end{array}$ & $\begin{array}{l}\text { Mengucapkan salam } \\
\text { 'Assalamu'alaikum' kepada laki-laki } \\
\text { maupun perempuan }\end{array}$ \\
\hline $\begin{array}{l}\text { Perempuan menggunakan baju } \\
\text { panjang dan kerudung serta } \\
\text { sarung tangan, tidak } \\
\text { menampakkan sama sekali muka } \\
\text { (membelakangi gambar) karena } \\
\text { konsep aurat dan haram } \\
\text { menurut Islam yang dianut } \\
\text { orang Arab Saudi. }\end{array}$ & $\begin{array}{l}\text { Menjawab salam 'Wa'alaikum salam' } \\
\text { kepada laki-laki maupun } \\
\text { perempuan. }\end{array}$ \\
\hline $\begin{array}{l}\text { Gambar perempuan yang } \\
\text { menampakkan wajah, kedua } \\
\text { belah mata sengaja ditutup. }\end{array}$ & $\begin{array}{l}\text { Menjawab salam "Bikhairin wa al- } \\
\text { Hamdulillah" }\end{array}$ \\
\hline
\end{tabular}

Bab II Al-Usrah (Keluarga)

\begin{tabular}{ll}
\hline \multicolumn{1}{c}{ Budaya Arab } & \multicolumn{1}{c}{ Budaya Islam } \\
\hline $\begin{array}{c}\text { Ekspresi kekaguman } \\
\text { dengan mengucapkan }\end{array}$ Masya'a Allah" & $\begin{array}{l}\text { Mengucapkan salam } \\
\text { 'Assalamu'alaikum' }\end{array}$ \\
$\begin{array}{l}\text { Memperkenalkan ayah dan ibu } \\
\text { tanpa mengucapkan panggilan } \\
\text { dalam keluarga }\end{array}$ & $\begin{array}{l}\text { Menjawab salam 'Wa'alaikum } \\
\text { salam' }\end{array}$ \\
$\begin{array}{l}\text { Ekspresi kekaguman dengan } \\
\text { mengucapkan "Masya'a Allah" }\end{array}$ & $\begin{array}{l}\text { Mengucapkan “Sallahu 'alaihi wa } \\
\text { sallam" setelah mendengar kata } \\
\text { Rasul }\end{array}$ \\
Memperkenalkan ayah dan ibu & Berwudhu \\
tanpa mengucapkan panggilan & \\
\hline
\end{tabular}


Siti Rohmah Soekarba

\begin{tabular}{|c|c|}
\hline \multicolumn{2}{|l|}{ dalam keluarga } \\
\hline $\begin{array}{l}\text { Perempuan menggunakan baju } \\
\text { panjang dan kerudung serta } \\
\text { sarung tangan, tidak } \\
\text { menampakkan sama sekali muka } \\
\text { (membelakangi gambar), kecuali } \\
\text { anak kecil karena konsep aurat } \\
\text { dan haram menurut Islam yang } \\
\text { dianut orang Arab Saudi. }\end{array}$ & Membaca Quran \\
\hline Geneologi Keluarga Nabi & Salat di Musalla \\
\hline $\begin{array}{l}\text { Mengucapkan "Allahu Akbar, } \\
\text { Allahu Akbar" setelah mendengar } \\
\text { panggilan salat }\end{array}$ & Mengajak anak-anak salat di masjid \\
\hline & $\begin{array}{l}\text { Di akhir pelajaran diperdengarkan } \\
\text { bacaan ayat-ayat Quran, melatih } \\
\text { pelafalan hurf 'ain: } \\
\text { 1. Surat Syarah ayat } 5-6 \\
\text { 2. Surat Maryam ayat } 84 \\
\text { 3. Surat Al-Naba' ayat } 1-2 \\
\text { 4. Surat Al-Akhqaf ayat } 15 \\
\text { 5. Surat Al-Kafirun ayat } 1-6\end{array}$ \\
\hline
\end{tabular}

Bab III Al-Sakan (Tempat Tinggal)

\begin{tabular}{|c|c|}
\hline Budaya Arab & Budaya Islam \\
\hline $\begin{array}{ll}\text { Mengucapkan } & \text { salam } \\
\text { "Assalamu'alaikum" } & \end{array}$ & $\begin{array}{l}\text { Mengucapkan salam } \\
\text { 'Assalamu'alaikum' }\end{array}$ \\
\hline $\begin{array}{l}\text { Menjawab salam "Wa'alaikum } \\
\text { salam" }\end{array}$ & Menjawab salam 'Wa'alaikum salam' \\
\hline $\begin{array}{l}\text { Semua percakapan antara laki-laki } \\
\text { dengan laki-laki }\end{array}$ & $\begin{array}{l}\text { Di akhir pelajaran diperdengarkan } \\
\text { bacaan ayat-ayat Quran, melatih } \\
\text { pelafalan huruf ha: } \\
\text { 1. Surat Al-Fatihah ayat } 1-3 \\
\text { 2. Surat Al-Adiyah ayat } 1-3 \\
\text { 3. Surat Al-Fath ayat } 1\end{array}$ \\
\hline
\end{tabular}

Indonesian Journal of Arabic Studies, Volume (1), Issue (2), November 2019 
Siti Rohmah Soekarba

4. Surat Al-Insyiqaq ayat 8

\section{Surat Al-Nahl ayat 6}

Orang Arab bertempat tinggal di rumah dan di apartemen.

Orang Arab mencari apartemen sewa. Yang akan menyewa dan yang menyewakan keduanya adalah laki-laki.

Percakapan antara penjual dan pembeli, keduanya laki-laki

Bentuk keramah-tamahan penjual kepada pembeli dengan mengucapkan "Ayyu khidmah" (Ada yang dapat saya bantu?)

Laki-laki berbelanja keperluan perabotan rumah tangga

Bab IV Al-Hayatu al-Yaumiyyah (Kehidupan Sehari-hari)

\section{Budaya Arab \\ Budaya Islam}

Pergi ke sekolah menggunakan bis Salat Subuh di masjid atau mobil pribadi

Pembagian pekerjaan rumah yang Setelah salat Subuh tidak tidur sama antara anak laki-laki dan kembali, tetapi membaca Quran

anak perempuan. Anak

perempuan menyapu kamar tidur,

anak laki-laki menyapu ruang

tamu dan mencuci baju.

Nenek mencuci piring, sementara

kakek membaca Quran

Bangun tidur lebih siang Pembagian pekerjaan rumah yang (terlambat) pada saat hari libur. sama antara anak laki-laki dan anak perempuan. Anak perempuan menyapu kamar tidur, anak laki-laki menyapu ruang tamu dan mencuci baju. 
Siti Rohmah Soekarba

\begin{tabular}{|c|c|}
\hline $\begin{array}{l}\text { Menunaikan salat Jumat di } \\
\text { masjid raya. }\end{array}$ & $\begin{array}{l}\text { Menunaikan salat Jumat di masjid } \\
\text { raya. }\end{array}$ \\
\hline $\begin{array}{l}\text { Anak laki-laki mencuci piring, } \\
\text { menyetrika, mencuci baju, dan } \\
\text { menyapu ruang tamu }\end{array}$ & $\begin{array}{l}\text { Di akhir pelajaran diperdengarkan } \\
\text { bacaan ayat-ayat Quran, melatih } \\
\text { pelafalan huruf tha: } \\
\text { 1. Surat Al-Nur ayat } 26 \\
\text { 2. Surat Al-Tur ayat } 1-2 \\
\text { 3. Surat Ali Imran ayat } 32 \\
\text { 4. Surat Al-Thariq ayat } 1-2 \\
\text { 5. Surat Al-Hamzah ayat } 4-5 \\
\text { 6. Surat Al-Syuara' ayat } 173 \\
\text { 7. Surat Al-R'ad ayat } 28 \\
\text { 8. Surat Al-Baqarah ayat } 184\end{array}$ \\
\hline $\begin{array}{l}\text { Perempuan menggunakan baju } \\
\text { panjang dan kerudung serta } \\
\text { sarung tangan, tidak } \\
\text { menampakkan sama sekali muka } \\
\text { (membelakangi gambar), karena } \\
\text { konsep aurat dan haram menurut } \\
\text { Islam yang dianut orang Arab } \\
\text { Saudi. }\end{array}$ & \\
\hline
\end{tabular}

Bab V Al-Ta'am wa al-Syarab (Makanan dan Minuman)

Budaya Arab Budaya Islam

Orang Arab makan tiga kali Suami mengucapkan salam

dalam sehari: sarapan pagi (al- "Assalamu'alaikum" kepada istri.

fatur), makan siang (al-ghada')

dan makan malam (al-'asya').

Orang Arab makan siang dengan Di akhir pelajaran diperdengarkan daging, ayam, nasi, dan roti bacaan ayat-ayat Quran latihan pengucapan huruf qaf:

1. Surat Al-Falaq ayat $1-4$

2. Surat $\mathrm{Sad}$ ayat 84

3. Surat Al-Ankabut ayat 16

4. Surat Qaf ayat 1 
Siti Rohmah Soekarba

\section{Surat Al-Qori'ah ayat $1-2$ \\ 6. Surat Al-Shafat ayat 31}

Ada juga yang makan ikan, salad, dan buah-buahan.

Penumpang perempuan

(musafirah) dan pramugari

(mudhifa) digambarkan dengan

perempuan paruh baya yang

gemuk, menggunakan baju

panjang, menggunakan kerudung,

dan mukanya tidak ditampilkan.

Berlawanan dengan realitas

pramugari yang sesungguhnya:

muda, langsing, tidak

mengenakan kerudung.

Makanan yang ditawarkan di dalam pesawat: ikan, nasi, kurma, dan anggur. Minuman yang ditawarkan adalah teh dan kopi susu.

Suami mengucapkan salam

"Assalamu'alaikum" kepada istri.

Budaya patriarkhi: Suami lapar, meminta makan kepada istrinya, namun melihat banyak makanan di meja (ikan, daging, ayam, nasi, dan buah-buahan), dia mempertanyakannya. Suami tidak tahu ada mertua datang di ruang tamu. Dari mana datangnya? Mungkin baru bangun. Orang Arab mempunyai kebiasaan bangun siang hari.

Orangtua yang bertandang ke rumah anak perempuannya 
Siti Rohmah Soekarba

\begin{tabular}{l}
\hline disebut dengan duyuf(tamu). \\
Sekalipun tamu berdua \\
(mutsanna), namun disebutkan \\
dalam bentuk jamak untuk \\
penghormatan (ihtiram). \\
Perempuan menggunakan baju \\
panjang dan kerudung serta \\
sarung tangan, tidak \\
menampakkan sama sekali muka \\
(membelakangi gambar), karena \\
konsep aurat dan haram menurut \\
Islam yang dianut orang Arab \\
Saudi.
\end{tabular}

Bab VI Al-Salah (Salat)

\section{Budaya Arab}

Salat lima waktu di masjid

Salat Subuh di rumah karena tidak mendengar suara panggilan adzan.
Salat lima waktu di masjid

Mengucapkan terima kasih disertai doa "jazaka Allah khairan". (semoga Allah membalas kebaikanmu)
Menyapa seseorang di bandara. Mengucapkan

"Assalamu'alaikum" menjawab salam "Wa'alaikum salam".

Menerima usulan meletakkan jam di samping tempat tidur dan mengapresiasi usulan tersebut dengan mengucapkan terima kasih "jazaka Allah khairan" (semoga Allah membalas kebaikanmu)

\section{Percakapan antara laki-laki dan} laki-laki..
Bepergian ke Mekkah untuk salat di Masjidil Haram dan ke Madinah untuk salat di Masjid Nabi. 
Siti Rohmah Soekarba

\begin{tabular}{|c|c|}
\hline & $\begin{array}{l}\text { Mengucapkan kata "insya Allah" } \\
\text { untuk merencanakan sesuatu. }\end{array}$ \\
\hline $\begin{array}{lr}\text { Menyapa seseorang di bandara. } \\
\text { Mengucapkan } & \text { salam } \\
\text { "Assalamu'alaikum" } & \text { dan }\end{array}$ & $\begin{array}{l}\text { Di akhir pelajaran diperdengarkan } \\
\text { bacaan ayat-ayat Quran latihan } \\
\text { pengucapan huruf sad: }\end{array}$ \\
\hline $\begin{array}{l}\text { menjawab salam "Wa'alaikum } \\
\text { salam". }\end{array}$ & $\begin{array}{l}\text { 1. Surat Al-Asr ayat } 1-3 \\
\text { 2. Surat Al-Safat ayat } 1 \\
\text { 3. Surat Al-Qalam ayat } 5 \\
\text { 4. Surat Lukman ayat } 17 \\
\text { 5. Surat Al-Ahzab ayat } 35 \\
\text { 6. Surat Lukman ayat } 19\end{array}$ \\
\hline
\end{tabular}

Bab VII Al-Dirasah (Pelajaran)

\begin{tabular}{|c|c|}
\hline Budaya Arab & Budaya Islam \\
\hline $\begin{array}{l}\text { Sekolah } 5 \text { hari dalam seminggu } \\
\text { dimulai dari hari Sabtu, } \\
\text { Minggu, Senin, Selasa, Rabu }\end{array}$ & $\begin{array}{l}\text { Mengucapkan syukur dengan } \\
\text { berkata "Al-hamdulillah" } \\
\text { syukur kepada Allah) }\end{array}$ \\
\hline Libur hari Kamis dan Jumat & $\begin{array}{l}\text { Mengucapkan kata "insya Allah" } \\
\text { untuk merencanakan sesuatu. }\end{array}$ \\
\hline $\begin{array}{l}\text { Mata pelajaran Kebudayaan } \\
\text { Islam, Bahasa Arab, } \\
\text { Matematika, Sains, dan } \\
\text { Komputer. }\end{array}$ & $\begin{array}{l}\text { Di akhir pelajaran diperdengarkan } \\
\text { bacaan ayat-ayat Quran, latihan } \\
\text { pendengaran dan pengucapan } \\
\text { huruf 'ghain: } \\
\text { 1. Surat Al-Kahfi ayat } 86 \\
\text { 2. Surat Al-Syarah ayat } 7-8 \\
\text { 3. Surat Al-'Alaq ayat } 6-7 \\
\text { 4. Surat Fatir ayat } 5 \\
\text { 5. Surat Al-Rum ayat } 2-3 \\
\text { 6. Surat Al-Safat ayat } 32 \\
\text { 7. Surat Al-Munafiqun ayat } 6 \\
\text { 8. Surat Al-Qasas ayat } 63 \\
\text { 9. Surat Ali Imran ayat } 161\end{array}$ \\
\hline $\begin{array}{l}\text { Ujian berlangsung pada bulan } \\
\text { Sya'ban. }\end{array}$ & \\
\hline
\end{tabular}


Siti Rohmah Soekarba

Tahun ajaran berakhir pada

bulan Ramadhan.

Liburan berlangsung selama 3

bulan .

Percakapan antara dua

perempuan, orang Suriah dan

Arab Saudi. Yang satu kuliah di

Universitas Damaskus Fakultas

Kedokteran dan satunya di

Universitas Ummul Qura

Fakultas Pendidikan.

Anak SMA pergi ke sekolah

menggunakan mobil sendiri

Bab VIII Al-Amal (Pekerjaan)

\section{Budaya Arab}

Budaya Islam

\begin{tabular}{ll}
\hline Percakapan antara dua laki-laki & Menyatakan rencana ke depan \\
tentang pekerjaan. Seorang dokter dengan mengucapkan "insya' \\
bekerja di rumah sakit selama 8 Allah". \\
jam; seorang insinyur bekerja di \\
perusahaan selama 7 jam. Mereka \\
mencintai pekerjaannya (Umum)
\end{tabular}

Percakapan 6 mahasiswa laki-laki yang akan bekerja sesuai dengan ilmu dan fakultas yang dipilihnya: dokter, apoteker, perawat, insinyur, pilot, dan guru (Umum)

Percakapan antara dua perempuan tentang pekerjaan dan jumlah anak mereka: guru SD dan SMA

Guru SD mempunyai 5 anak.

Perempuan menggunakan baju 
Siti Rohmah Soekarba

\begin{tabular}{l}
\hline panjang dan kerudung serta \\
sarung tidak \\
menampakkan sama sekali muka \\
(membelakangi gambar), karena \\
konsep aurat dan haram menurut \\
Islam yang dianut orang Arab \\
Saudi. . \\
Jumlah anak dalam keluarga: 3 \\
sampai 9 anak. \\
Gambar yang ditampilkan semua \\
bayi, seolah-olah kembar 3 sampai \\
kembar 9, dan warna kulit anak- \\
anak berbeda-beda.
\end{tabular}

Bab IX Al-Tasawwuq (Berbelanja)

\begin{tabular}{|c|c|}
\hline Budaya Arab & Budaya Islam \\
\hline $\begin{array}{l}\text { Percakapan antara dua laki-laki } \\
\text { transaksi di toko buku di negara } \\
\text { Arab Saudi karena menggunakan } \\
\text { mata uang Riyal. }\end{array}$ & $\begin{array}{l}\text { Di akhir pelajaran diperdengarkan } \\
\text { bacaan ayat-ayat Quran, latihan } \\
\text { pendengaran dan pengucapan huruf } \\
\text { 'dha: } \\
\text { 1. Surat Al-Fatih ayat } 16 \\
\text { 2. Surat Al-Nahl ayat } 58 \\
\text { 3. Surat Al-Rahman ayat } 76 \\
\text { 4. Surat Lukman ayat } 13 \\
\text { 5. Surat Al-Nisa ayat } 57 \\
\text { 6. Surat Hud ayat } 122 \\
\text { 7. Surat Lukman ayat } 13\end{array}$ \\
\hline $\begin{array}{l}\text { Penjual mengucapkan "ahlan wa } \\
\text { sahlan" (selamat datang) kepada } \\
\text { pembeli yang datang sebagai } \\
\text { bentuk keramahtamahan. }\end{array}$ & \\
\hline $\begin{array}{l}\text { Bentuk negasi diakhiri dengan } \\
\text { ucapan terima kasih, "la, } \\
\text { syukran!" (tidak, terima kasih) }\end{array}$ & \\
\hline
\end{tabular}


Siti Rohmah Soekarba

Mempersilakan dengan
mengucapkan "tafaddal" (silakan)
Perempuan mengenakan baju
panjang dan kerudung berwarna
hitam sambil menggendong anak
laki-lakinya, tidak menampakkan
sama sekali muka (membelakangi
gambar).

Percakapan antara penjual lakilaki dan pembeli perempuan di negara Irak atau Yordania karena menggunakan mata uang dinar.

Penjual menyapa pembeli
perempuan dengan salam
"marhaban, ayyu khidmah"
(Selamat datang, ada yang bisa
sayabantu?)
Perempuan berbelanja ikan,
daging, ayam, mentimun, tomat,
bawang, satu kotak telur, dan
kotakgaram kemeja di
Laki-laki berbelanja kang
sebuah negara Arab yangang dinar.
menggunakan mata uang

Bab X Al-Jawwu (Cuaca)

\section{Budaya Arab}

Budaya Islam

\begin{tabular}{|c|c|}
\hline $\begin{array}{l}\text { Percakapan antara suami dan } \\
\text { istri tentang cuaca. Si istri } \\
\text { menanyakan cuaca di luar rumah. } \\
\text { Budaya Arab, istri tinggal di } \\
\text { rumah jika suami sedang keluar } \\
\text { bekerja.. }\end{array}$ & $\begin{array}{l}\text { Suami mengucapkan terima kasih } \\
\text { kepada istri setelah dihidangkan } \\
\text { secangkir teh panas dengan } \\
\text { mengucapkan "baraka Allah fiki" }\end{array}$ \\
\hline $\begin{array}{l}\text { Musim gugur banyak hujan } \\
\text { turun. }\end{array}$ & $\begin{array}{l}\text { Mengucapkan "insya Allah" untuk } \\
\text { merencanakan pergi ke pasar pada }\end{array}$ \\
\hline
\end{tabular}




\begin{tabular}{|c|c|}
\hline & keesokan hari. \\
\hline $\begin{array}{l}\text { Seorang istri menunggu } \\
\text { suaminya pulang ke rumah untuk } \\
\text { minta meminta diantar ke pasar. }\end{array}$ & $\begin{array}{l}\text { Mengucapkan "insya Allah" untuk } \\
\text { merencanakan berlibur ke Tunisia }\end{array}$ \\
\hline $\begin{array}{l}\text { Menyetujui ide istri dengan } \\
\text { mengucapkan "hadzihi fikratun } \\
\text { tayyibatun' (Ini adalah ide yang } \\
\text { baik) }\end{array}$ & $\begin{array}{l}\text { Mengucapkan "Alhamdulillah" } \\
\text { karena musim panas sudah berlalu }\end{array}$ \\
\hline $\begin{array}{l}\text { Perempuan mengenakan baju } \\
\text { panjang dan kerudung berwarna } \\
\text { hitam dan kaus tangan hitam, } \\
\text { tidak menampakkan sama sekali } \\
\text { muka (membelakangi gambar). }\end{array}$ & \\
\hline $\begin{array}{l}\text { Percakapan antara dua laki-laki di } \\
\text { telpon tentang cuaca di London } \\
\text { pada musim dingin dan cuaca di } \\
\text { Riyadh. }\end{array}$ & $\begin{array}{l}\text { Di akhir pelajaran diperdengarkan } \\
\text { bacaan ayat-ayat Quran, latihan } \\
\text { pendengaran dan pengucapan huruf } \\
\text { dha: }\end{array}$ \\
\hline & $\begin{array}{l}\text { 1. Surat Al-Qiyamah ayat } 22-23 \\
\text { 2. Surat Al-Hujurat ayat } 12 \\
\text { 3. Surat Al-Syu'ara ayat } 4 \\
\text { 4. Surat Lukman ayat } 11 \\
\text { 5. Surat Al-Sajdah ayat } 3 \\
\text { 6. Surat Fatir ayat } 40 \\
\text { 7. Surat Hadid ayat } 21 \\
\text { 8. Surat Isra ayat } 88\end{array}$ \\
\hline $\begin{array}{l}\text { Cuaca musim semi di negara } \\
\text { Arabnyaman. }\end{array}$ & \\
\hline $\begin{array}{l}\text { Dua laki-laki merencanakan } \\
\text { liburan di padang pasir membawa } \\
\text { keluarga mereka. }\end{array}$ & \\
\hline
\end{tabular}

Bab XI Al-Nas wa Al-Amakin (Manusia dan Tempat-tempat)

Budaya Arab Budaya Islam

Percakapan antara dua laki-laki Waktu libur digunakan untuk pergi tentang kepindahan dari Irak ke ke Mekkah menunaikan salat dan 
Siti Rohmah Soekarba

Arab Saudi untuk bekerja. . ibadah umrah di Masjidil Haram.

Negara Irak adalah negara yang Mengucapkan "insya Allah" untuk indah dan kaya. Dia bahagia merencanakan berlibur ke Tunisia tinggal di Irak, mempunyai teman-teman di sana, tetapi harus meninggalkan negaranya, Jeddah adalah kota yang indah. Mengucapkan "Alhamdulillah" karena musim panas sudah berlalu

Waktu libur di tepi pantai kota Di akhir pelajaran diperdengarkan Jeddah. bacaan ayat-ayat Quran, latihan pendengaran dan pengucapan huruf tsa:

1. Surat Al-Maidah ayat 23

2. Surat Al-Ankabut ayat 13

3. Surat Al-Nisa' ayat 176

4. Surat Ibrahim ayat $26-27$

Orang Yaman sekolah di Arab Saudi, berkeluarga dan bekerja lebih dari sepuluh tahun dan bahagia tinggal di Arab Saudi.

Orang Yaman kembali ke negerinya hanya untuk liburan.

Perjalanan dari kota Jeddah ke Mekkah ditempuh dalam satu jam 30 menit.

Problem tinggal di kota yang banyak polusi, berisik, dan macet. Keputusan tinggal di kampung karena udara masih bersih dan tenang.

Tidak masalah setiap hari pergi kerja di kota dengan menggunakan kereta dengan jarak tempuh satu jam 30 menit. 
Siti Rohmah Soekarba

Bab XII Al-Hiwayat (Hobi)

\section{Budaya Arab}

Budaya Islam

Percakapan antar dua laki-laki Hobi membaca buku-buku dan tentang hobi mereka masing- majalah Islam atau majalah ilmiah. masing.

Hobi-hobi itu adalah membaca, Mengucapkan "Alhamdulillah" melancong, korespondensi, karena musim panas sudah berlalu olahraga, dan berlibur.

Mereka mempunyai perpustakaan Di akhir pelajaran diperdengarkan pribadi yang besar. bacaan ayat-ayat Quran, latihan pendengaran dan pengucapan huruf syin:

1. Surat Al-Buruj ayat 3

2. Surat Al-Nisa ayat 41

3. Surat Al-Nisa ayat 48

4. Surat Al-Takwir ayat $28-29$

5. Surat Ali Imran ayat 26

Mereka membaca buku tiga sampai

empat jam sehari.

Keduanya sepakat bahwa membaca

itu adalah hobi yang baik.

Percakapan antara dua laki-laki

tentang pameran kegemaran.

Pameran filateli, kaligrafi Arab, surat kabar dalam pelbagai bahasa, tata graha, tata boga, dan olah raga (sepak bola, renang, dan berkuda).

Guru perempuan menghadap papan tulis dan murid-murid perempuan menghadap ke papan tulis. Tidak terlihat muka-muka mereka.

Murid-murid perempuan
berpatisipasi dalam kelompok berpatisipasi dalam kelompok 
Siti Rohmah Soekarba

pencinta jurnalistik, kelompok

kebudayaan Islam, kelompok

komputer, kelompok sains,

kelompok bahasa Arab, dan

kelompok tata graha.

Bab XIII Al-Safar (Bepergian)

\title{
Budaya Arab
}

Budaya Islam

Percakapan antara petugas check in Mengucapkan "Assalamu'alaikum" desk di bandara dan seorang kepada petugas imigrasi dan penumpang laki-laki. dibalas "Wa'alaikum salam. Ahlan wa sahlan (selamat datang).

Petugas menyapa dengan kalimat Mengucapkan "Insya Allah" untuk "ayyu khidmah" (Ada yang bisa umroh yang diterima Allah. saya bantu?) .

Penumpang sudah reservasi dengan penerbangan Indonesia (GIA) dan menyerahkan tiketnya, tiket istrinya, dan tiket anak perempuan serta anak laki-lakinya. Serta menyerahkan paspor-paspor mereka.

Petugas memberi informasi agar datang ke bandara dua jam sebelum pesawat tinggal landas.
Mengucapkan terima kasih "Jazaka Allahu khairan"!

Di akhir pelajaran diperdengarkan bacaan ayat-ayat Quran, latihan pendengaran dan pengucapan huruf alif:

1. Surat Al-Rahman ayat $1-4$

2. Surat Al-Naba' ayat 31-35

3. Surat Al-Syam ayat $1-10$

\begin{abstract}
Petugas membalas ucapan terima kasih dengan mengucapkan "rihlah sa'idah" (semoga perjalanan menyenangkan), alih-laih "afwan' (kembali atau sama-sama).

Petugas imigrasi menanyakan
\end{abstract}

Indonesian Journal of Arabic Studies, Volume (1), Issue (2), November 2019 
Siti Rohmah Soekarba

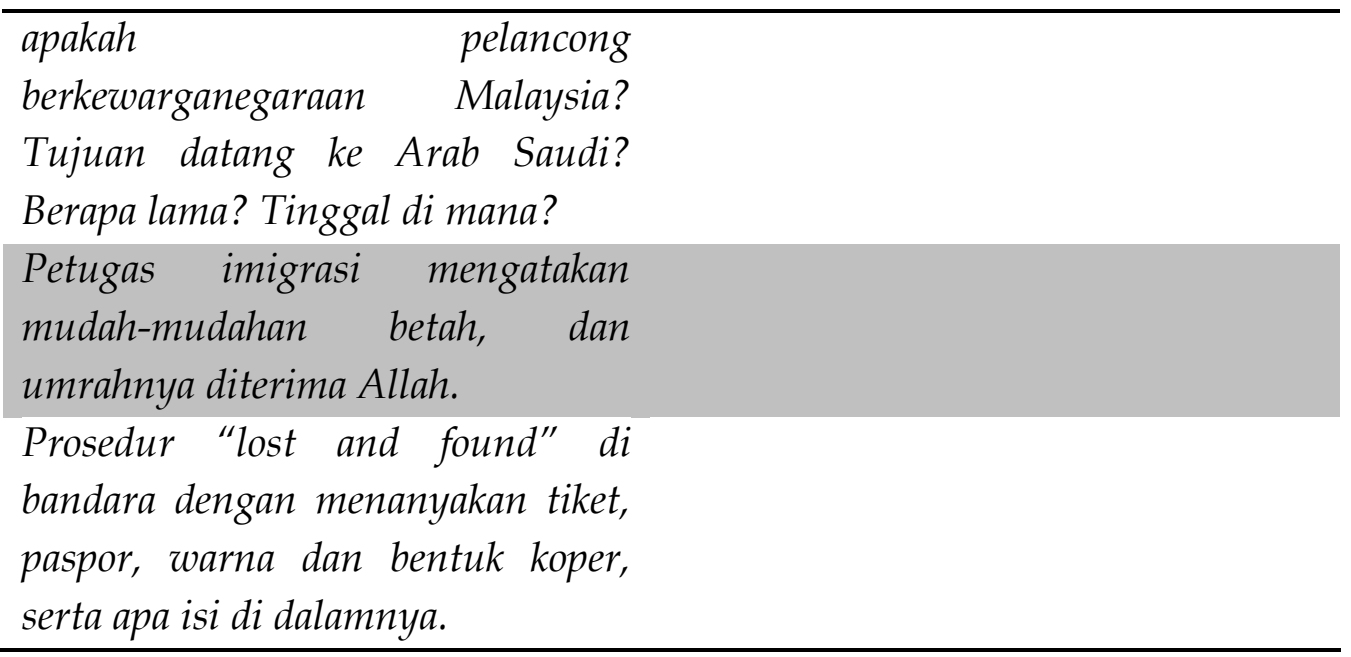

Bab XIV Al-Haj wa al-'Umrah (Haji dan Umrah)

\section{Budaya Arab}

Budaya Islam

Percakapan antar dua laki-laki Berpuasa, salat di Masjidi Haram tentang liburan. Liburan pada dan di Masjid Nabi

bulan Ramadhan.

Mengisi waktu liburan di Mekkah Ibadah umroh. Tiba di Miqat pada dan Madinah menunaikan ibadah saat matahari terbit. Mengenakan puasa, ibadah umrah, salat di baju ihram, dan berniat akan Masjidi Haram dan di Masjid menunaikan ibadah umrah.

Nabi.

Merayakan hari-hari raya di Tiba di Masjidil Haram sesudah Mekkah atau di Madinah. Asar dan merasa bahagia dapat berada di sana.

Merasa senang dan bahagia di Tawaf mengelilingi Ka'bah tujuh kedua kota suci tersebut. kali, kemudian salat sunah dua rakaat di belakang makam Nabi Ibrahim.

Percakapan antara seorang ayah Sai (lari-lari kecil) antara bukit Shafa dan anak laki-lakinya tentang dan Marwah tujuh kali, kemudian ibadah umrah dan haji tahallul (menggunting rambut atau mencukur rambut kepala). Mengganti baju ihram di hotel Wukuf di Arafah, pergi ke 
Muzdalifah, Mina, menyembelih kurban, dan mencukur rambut. Kembali ke Masjidil Haram untuk tawaf ifadzah. Sesudah melempar jumrah, melaksanakan tawaf wadha (perpisahan) pada tanggal 12 atau 13 Dzulhijjah.

Di akhir pelajaran diperdengarkan bacaan ayat-ayat Quran, latihan pendengaran dan pengucapan huruf ya:

1. Surat Al-Fatihah ayat 2-6

2. Surat Yasin ayat 1-5

3. Surat Taha $25-32$

Bab XV Al-Sihhah (Kesehatan)

\begin{tabular}{|c|c|}
\hline Budaya Arab & Budaya Islam \\
\hline $\begin{array}{l}\text { Percakapan antara pasien laki-laki di } \\
\text { sebuah rumah sakit. }\end{array}$ & $\begin{array}{l}\text { Tidak saling mengenal, tetapi } \\
\text { mengucapkan salam } \\
\text { "Assalamu'alaikum warahmatullahi } \\
\text { wabarakatuhu" dan dijawab } \\
\text { "Wa'alaikum salam warahmatullahiw } \\
\text { abarakatuhu". }\end{array}$ \\
\hline $\begin{array}{l}\text { Pasien pertama akan berkunjung ke } \\
\text { dokter gigi dan yang lainnya akan } \\
\text { berkunjung ke dokter THT. }\end{array}$ & $\begin{array}{l}\text { Guru mengucapkan salam kepada } \\
\text { muridnya "Assalamu'alaikum } \\
\text { warahmatullahi wabarakatuhu" dan } \\
\text { dijawab "Wa'alaikum salam } \\
\text { warahmatullahiw abarakatuhu". }\end{array}$ \\
\hline $\begin{array}{l}\text { Mereka melakukan janji terlebih } \\
\text { dahulu dan datang } 30 \text { menit } \\
\text { sebelum perjanjian bertemu dengan } \\
\text { dokter. }\end{array}$ & $\begin{array}{l}\text { Guru mengucapkan terima kasih } \\
\text { menerima surat keterangan sakit } \\
\text { dari muridnya. }\end{array}$ \\
\hline $\begin{array}{l}\text { Seorang guru laki-laki menanyakan } \\
\text { kepada murid laki-lakinya mengapa }\end{array}$ & $\begin{array}{l}\text { Murid mengucapkan } \\
\text { “alhamdulillah" untuk menyatakan }\end{array}$ \\
\hline
\end{tabular}


tidak hadir kemarin.

\section{Murid laki-laki tersebut menjawab} bahwa kemarin dia sakit flu dan demam yang berat. Sakit kepala dan suhu badan meninggu di malam hari. Dia pergi ke rumah sakit dengan mobil ambulans dan bertemu dengan dokter.

Guru mengenakan t-shirt dan Istri mendoakan suaminya agar bajunya tidak dimasukkan ke dalam sembuh dengan mengucapkan celana panjang. Tidak formal. bahwa kondisi kesehatannya baik. Istri menyapa suami dengan salam "Assalamu'alaikum warahmatullahi wabarakatuhu" dan dijawab "Wa'alaikum salam warahmatullahiw abarakatuhu".

\section{Percakapan antar suami istri tentang kondisi kesehatan sang suami.}

"syafaka Allah" (semoga Allah menyembuhmu) dan dijawab "syukran laka" (terima kasih)
Di akhir pelajaran diperdengarkan bacaan ayat-ayat Quran, latihan pendengaran dan pengucapan huruf waw:

1. Surat Al-Buruj ayat 1-7

2. Surat Al-Ghasyiyah ayat 1315

3. Surat Al-Syu'ara ayat 4

4. Surat Al-Ma' arij ayat 32-34

5. Surat Al-Tur ayat 1-6

6. Surat Al-Waqi'ah ayat $28-30$

Istri mengenakan baju panjang dan penutup kepala, wajah tidak ditampilkan karena menghadap ke kompor.

Bab XVI Al-'Utlah (Liburan)

\section{Budaya Arab}

Budaya Islam

\begin{tabular}{ll}
\hline Percakapan antara seorang anak & Dijelaskan dalam tradisi Islam ada \\
$\begin{array}{l}\text { dengan ayahnya tentang hari raya di } \\
\text { dalam Islam. }\end{array}$ & Adhari raya: Idul Fitri dan Idul \\
Percakapan seorang ayah dengan & Idul Fitri dirayakan pada tanggal 1 \\
\hline
\end{tabular}


anak-anaknya tentang rencana liburan dan menanyakan pendapat mereka.

Sang ayah menerima pendapat anaknya untuk berlibur di Mesir dan menjelaskan kepada mereka bahwa pergi menggunakan pesawat itu mahal, sehingga memutuskan menggunakan kapal laut yang lebih murah.

Kedua anak mengucapkan terima kasih kepada ayah mereka karena pendapatnya diterima. "Syukran laka ya abi".
Syawwal, setelah berpuasa di bulan Ramadhan
Kewajiban menunaikan zakat bagi setiap Muslim sebelum salat Idul Fitri. Menunaikan salat Idul Fitri dan berkunjung ke keluarga dan para sahabat.
Percakapan seorang guru dengan 5 murid laki-lakinya menanyakan kemana mereka akan menghabiskan musim panas.
1. Di kampung dengan kakek- Mengucapkan "Alhamdulillah" nya. Tempat di sana tenang, karena musim panas sudah berlalu dan udaranya bersih.

2. Di ibukota dengan pamannya. Akan mengunjungi perpustakaanperpustakaan dan museummuseum.

3. Mendaki gunung dengan teman-temannya.

4. Di kota Mekkah dengan keluarga. Menunaikan ibadah umrah dan haji dan 
mengunjungi Masjid

Nabawi.

5. Pulang kampung membantu

ayah di ladang.

\section{Guru mengucapkan "utlah}

sa'idah" (selamat berlibur) dan

dibalas oleh murid-muridnya "utlah

sa'idah".

Berikut adalah ringkasan nilai-nilai budaya Arab dan Islam yang ditampilkan dalam buku:

1. Salam 'Assalamu'alaikum' pada setiap awal percakapan baik dengan teman, keluarga, maupun dengan orang asing yang belum dikenal.

2. Memperkenalkan geneologi keluarga Nabi Muhammad SAW dan membacakan salawat "shallallahu 'alaihi wa sallam' ketika mendengarkan seseorang menyebutkan nama Rasulallah.

3. Konsep keluarga terdiri dari ayah, ibu, anak, kakek, dan nenek.

4. Selalu diperdengarkan ayat-ayat al-Quran di akhir bab sebagai latihan pendengaran (maharatu al-kalam) dan latihan pengucapan huruf-huruf dan suara (harf wa aswat).

5. Perempuan menggunakan baju panjang dan penutup kepala (hijab) sebagai representasi perempuan Muslim.

6. Percakapan tentang salat di masjid, bangun pagi untuk salat Subuh, aktivitas membaca Quran setelah salat Subuh.

7. Berwudlu di kamar mandi

8. Membaca Quran pada hari Jumat (hari libur).

9. Perempuan tidak ditampilkan muka depan, tetapi dari samping (ada anggapan haram menampilkan muka perempuan karena dianggap aurat)

10. Perempuan menggunakan sarung tangan (konsep aurat)

11. Percakapan laki-laki dengan laki-laki

12. Percakapan perempuan dengan perempuan. Dapat dipahami untuk menjelaskan ism mudzakkar dan ism muannas (kata benda 
berjenis kelamin laki-laki dan perempuan), dapat menjelaskan ketatnya pemisahan antara laki-laki dan perempuan.

13. Ekpresi misalnya Masya'a Allah untuk menyatakan kekaguman, subhanallah, alhamdulillah, insya Allah, Allahu akbar, dll.

14. Pembagian kerja yang sama antara anak laki-laki dan perempuan. Baik anak perempuan dan laki-laki membantu mengerjakan pekerjaan rumah pada hari libur.

15. Orangtua yang berkunjung ke rumah anak perempuan yang sudah menikah dianggap sebagai tamu (dzuyuf).

16. Penggunaan bentuk jamak untuk panggilan kepada 1 orang sebagai bentuk ihtiram (penghormatan). Alih-alih menggunakan anta (kamu, anda), digunakan antum (kalian semua).

17. Jenis-jenis makanan Arab seperti daging, ayam, ikan. Buahbuahan Arab seperti kurma dan anggur.

18. Pemaparan bahwa orang Arab tinggal di apartemen dengan mengajukan pertanyaan apakah tinggal di apartemen atau di sebuah rumah.

19. Mencari apartemen dilakukan oleh laki-laki dan belanja perabot rumah tangga untuk mengisi rumah atau apartemen dilakukan juga oleh laki-laki (Al-Fauzan 2004)

\section{Simpulan}

Pemakaian bahasa Arab sebagai salah satu bahasa resmi dalam forum internasional telah menempatkan bahasa Arab untuk berperan penting dan sebagai salah satu alat komunikasi dalam hubungan diplomasi internasional. Peningkatan peranan bahasa Arab yang menjadi salah satu alat komunikasi dalam diplomasi internasional ini didukung oleh semakin besarnya peranan negara-negara Arab penghasil minyak dalam dunia perekonomian internasional. Peran ini, tentu saja, menambah dan menjadi daya tarik perhatian dunia terhadap pengajaran bahasa Arab.

Bahasa Arab patut diperhitungkan sebagai bagian dari peradaban dunia. Melihat fakta tersebut, dunia tetap membutuhkan bahasa Arab. Dengan demikian, bahasa Arab tetap akan bertahan, malah membuka peluang bagi kebutuhan sumber daya manusia yang 
menguasai bahasa ini. Berkenaan dengan hal tersebut, pengajaran bahasa Arab dengan perspektif lintas budaya seperti yang diwakili oleh buku Al-Arabiyyatu bayna Yadaik baik digunakan sebagai buku ajar. Buku ini memuat bahasa Arab baku dan modern dan metode pengajaran secara gradual, up to date dan aplikatif, sehingga keluhan kurang tersedianya bahan ajar yang baik (Taufikurrahman 2015) dapat diatasi dengan buku teks ini.

Karena buku Al-Arabiyyatu bayna Yadaik merepresentasikan 4 kompetensi yaitu pertama, kemahiran menyimak (maharatu al-istima'); kedua, membaca (maharatu al-qira'ah); ketiga, berbicara (maharatu alkalam); dan keempat, menulis (maharatu al-kitabah), buku ini dipakai oleh Program Studi Arab Fakultas Ilmu Pengetahuan Budaya Universitas Indonesia sebagai buku utama pengajaran kemahiran bahasa yang diyakini dapat mewujudkan visi, misi, dan kompetensi utama lulusannya dalam berkomunikasi dan menerapkan kajian sosial budaya Arab. Juga buku ini dapat dijadikan sebagai alternatif pembelajaran bahasa Arab berbasis lintas budaya, yang dianggap cocok dengan pembelajar di Indonesia yang mayoritas mengenal budaya Islam sejak kecil. Melalui uji coba pemakaian buku ini, kemudian digunakan pada kursus bahasa Arab untuk umum yang diselenggarakan oleh Lembaga Bahasa Internasional Fakultas Ilmu Pengetahuan Budaya Universitas Indonesia dan dipakai juga pada pengajaran di Sekolah Pendidikan Luar Negeri (SEKDILU) Departemen Luar Negeri RI Jakarta

\section{Referensi}

Ainin, M. (2007). Metodologi Penelitian Bahasa Arab. Malang: Hilal Pustaka.

Al-Fauzan, A. B. I., Husain, M. A. T., \& Fadhl, Mu. A. K. M. (2004). AlArabiyah Baina Yadaik. Riyadh: Al-Arabiyya lil Jami'.

Aziez, F., \& Al-Wasilah, A. C. (1996). Pengajaran Bahasa Komunikatif. Bandung: PT Remaja Rosda karya.

Effendi, A. F. (2005). Metodologi Pengajaran Bahasa Arab (3 ed.). Malang: Misykat.

Hadi, S. (1995). Bahasa Arab dan Khazanah Sastra Keagamaan di 
Indonesia. Humaniora, 2, 87-95.

Kuipers, J. C., \& Askuri. (2017). Islamization and Identity in Indonesia: The Case of Arabic Names in Java. Indonesia, 103(April), 25-49. https:// doi.org/10.5728/indonesia.103.0025

Letmiros, L. (2019). Arabic: Why Indonesians Have To Learn It? International Review of Humanities Studies, 4(2), 610-622. https:// doi.org/10.7454/irhs.v4i2.166

Miles, M. B., \& Huberman, A. M. (2007). Analisis Data Kualitatif: Buku Sumber Tentang Metode-Metode Baru. (T. R. Rohidi, Penerj.). Jakarta: Universitas Indonesia.

Rahmi, N. (2018). Wujud Bahasa Arab Dalam Memperkaya Kebudayaan Indonesia. Al-Fathin: Jurnal Bahasa Dan Sastra Arab, 1(2), 159-164.

unesco.org. (2017). World Arabic Language Day 2017: focus on new technologies. Diambil 2 Februari 2019, dari https:/ / en.unesco.org/news/world-arabic-language-day-2017focus-new-technologies 